\title{
Erratum to: Influence of Electropolishing and Magnetoelectropolishing on Corrosion and Biocompatibility of Titanium Implants
}

Zia ur Rahman, Luis Pompa, and Waseem Haider

Erratum to: JMEPEG (2014) 23:3907-3915

DOI 10.1007/s11665-014-1205-3

The bibliographic information in Reference 12 of this article as published should be replaced with the following information:

T. Hryniewicz, R. Rokicki, and K. Rokosz, Corrosion and Surface Characterization of Titanium Biomaterial after Magnetoelectropolishing, Surf. \& Coat. Technol., 2009, 203, p 15081515

The online version of the original article can be found under doi: 10.1007/s11665-014-1205-3.

Zia ur Rahman, Luis Pompa, and Waseem Haider, Department of Mechanical Engineering, University of Texas Pan American, $1201 \mathrm{~W}$ University Dr., Edinburg, TX 78539. Contact e-mail: haiderw@ utpa.edu. 